\title{
Medical doodles: 30 minutes well spent
}

$\mathrm{W}$ hen we think of medical students learning, we think of them listening to lectures and taking reams of notes. Not so for many visually inspired learners. A recent survey of medical students indicated that more than $50 \%$ expressed a strong preference for multiple modes of information delivery, including visual, auditory and kinesthetic. ${ }^{1}$ A case in point is Michiko Maruyama, a second-year University of British Columbia medical student with an undergraduate degree in industrial design who incorporates artmaking into her daily learning routine. In the following interview, I explore the role imagery and art-making play in her note-taking, learning, studying and her plans for integrating art into her practice.

Can you describe your background prior to entering medical school?

"I completed a degree in industrial design at the University of Alberta. The program was 'project' driven. We were trained to look at the system as a whole; we looked at what works and where there were design problems."

What was the transition like from your industrial design background into medical school?

"I was afraid [going into medicine] I would lose my creative side. I've always done art and never taken a big break. I worried that if I stopped I would go to a canvas and not be able to imagine anything there. I didn't want to lose my artistic ability to express my emotions — in other words to be an artist."

\section{Did that happen?}

"Quite the opposite, I have never felt so artistic. I am focusing on art differently. It's like I regained my artistic flair. Before medical school, art was my profession. I did art for my clients; in medical school I do art for myself and for my learning."

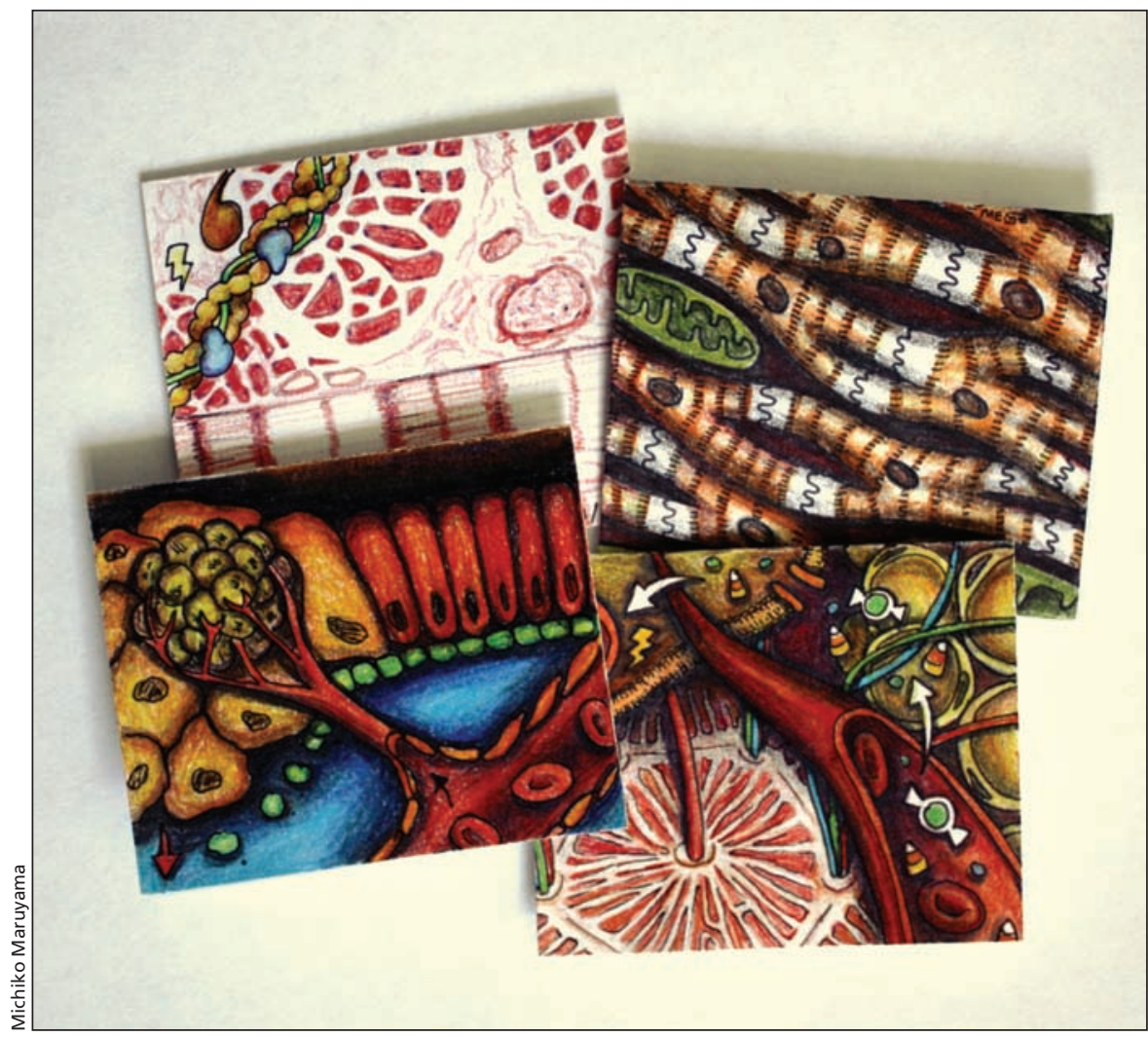

Four daily doodles illustrating a variety of anatomical, histological and clinical concepts.

Can you describe how art-making and imagery have contributed to your learning in medical school?

"I don't take traditional notes during lectures, I am afraid I will miss something when I am writing. Instead I pay close attention, then jot down key words, for example words I am not familiar with or a new main topic. In the evening I take an hour to reflect and write down what I learned.

I compare that to my list of key words, looking to see where the holes are, it's a way to self check. Then I imagine how to put it all together to form an image that best represents what I learned. After I get that visual I put on the timer for 30 minutes and I use pencil crayons to draw my 'daily doodle' on a 3 " $\times 5$ " index card."
What is the significance of drawing for exactly 30 minutes?

"It is easy with art to keep going. Initially I was told I was 'wasting time' on drawing when I should be studying. My response was that it was not a waste of time since I was doing what I enjoy while I studied. [The comment] made me conscious of time so I set a timer and did my drawing efficiently in 30 minutes."

Do these daily doodles play a role in reviewing material or studying for exams?

"Yes definitely. When I look at the daily doodles they trigger my memory. I can take myself back to the time when I was reflecting and drawing the doodle. I also remember what I did that particular day." 
You could argue that it is the selfreflection, not the drawing, that is promoting your recall.

"Actually, last year during one week I stopped doodling, however, I still maintained the reflection and I wrote even more notes in the traditional way. That was the one week that I had difficulty in remembering [the material]. It was the only week my grades dipped during the course."

Siegel $^{2}$ describes the process of moving between text and imagery as transmediation and notes that it promotes reflective and generative thinking. Sunni Brown" defines doodling as "to make spontaneous marks to help yourself think" and Andrade ${ }^{4}$ contends that doodling enhances verbal information retention. Does this resonate with you?

"For me the doodles generate links between different concepts, they fill in gaps of knowledge. It's not until I doodle that I think about how everything comes together. When I look at the doodles they have all this meaning.

When I doodle I find out what I know and what I don't. I catch details that I wouldn't have been aware of. There is a difference between looking at a prepared [textbook] drawing and going to a blank piece of paper and creating an image. [When I draw] I have to figure out what pieces go where and how things interact."

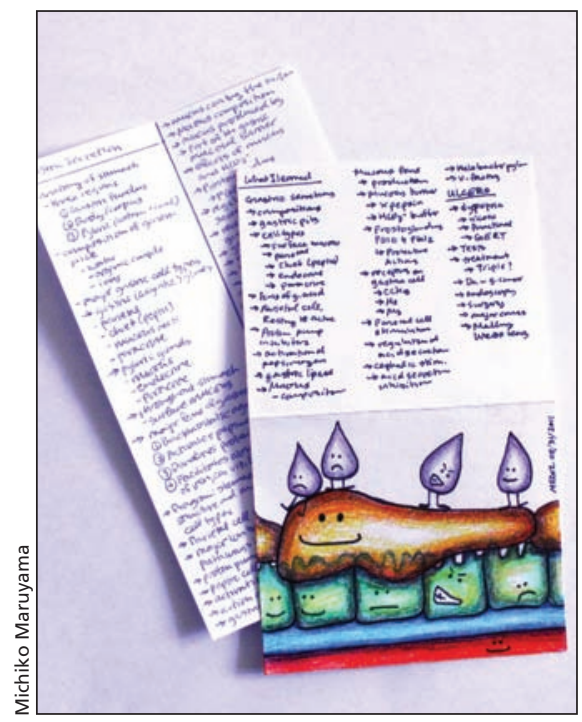

Michiko's end product: key word list, plus "What I learned" plus daily doodle (physiology of gastric secretion and peptic ulcer disease).
Do others benefit from your daily doodles?

"I began to post the daily doodles on my Facebook page along with a title and a short description of what I learned that day. Facebook friends [medical students from across Canada] began to tag the doodles adding labels to the various anatomical structures. Students added comments to my Facebook page saying that they used the doodles as a way to study. One student told me that during her exam she just visualized one of my doodles in order to remember a particular concept."

How do you hope to integrate art into your practice as a doctor?

"I hope to integrate industrial design into medicine by making medical tools and developing procedures and techniques. This past year one of my preceptors challenged me to develop a better tenaculum [a device that stabilizes the cervix during insertion of an IUD (intrauterine device)] that would not cause pain and bleeding.

I also want to explore the value of art in communication. I'd like to sit with my patients and communicate with art, draw what is happening to develop a common level of understanding. I am also illustrating children's books focused on medical topics as a way to educate with art."

How have artist-doctor role models inspired you?

"I have had three important physician role models: Dr. Andrew Seal (surgeonartist), Dr. Jaap Hamburger (cardiologistcomposer) and Dr. Sean Robinson (urologist-designer). They are people to talk with and discuss the challenges I face. Through them I learned that other artistdoctors are successful in both disciplines. To hear that is inspiring."

"Hearing more from my fellow students who have artistic talents is also very helpful."

\section{Linking art-making, identity and learning}

To summarize, Monrouxe ${ }^{5}$ suggests that a medical student's personal identity can either facilitate or constrain their professional identity formation. Students that find positive ways to integrate their personal identity into their professional identity are more likely to avoid what Costello ${ }^{6}$ calls "identity dissonance," and its associated, potentially disruptive behaviors. Maintaining one's personal identity as an artist during medical school, however, is not without its potential barriers. Lee and Graham $^{7}$ found that the stress associated with a very demanding curriculum was amplified by what they called "relaxation guilt," associated with creating opportunities to relax (by art or any other means). Reinforcing the link between art-making and learning, however, provides a rationale for encouraging its use throughout training. This can be done by exposure to physicianartist role models or student-artist mentoring groups.

It seems to me, in medical school, being able to successfully combine learning with stress release, and at the same time exercising one's creativity is a very good use of 30 minutes a day spent with a dozen coloured pencils.

\section{Carol Ann Courneya PhD}

Associate professor

Faculty of Medicine

University of British Columbia

Vancouver, BC

Michiko Maruyama is now a second-year student in the Northern Medical Program (in Prince George), University of British Columbia. To view more daily doodles, emailmmichiko@interchange.ubc.ca.

\section{References}

1. Lujan H, DiCarlo S. First year medical students prefer multiple learning styles. Adv Physiol Educ 2006;30:13-16.

2. Seigel M. More than words: the generative power of transmediation for learning. Canadian Journal of Education, 1995; 20: 455-475.

3. Sunni Brown: Doodlers unite [video]. New York (NY): TED Conferences; 2011. Available: www .ted.com/talks/sunni_brown.html (accessed 2012 Feb. 1).

4. Andrade J. What does doodling do? Appl Cogn Psychol 2010;24:100-6.

5. Monrouxe LV. Identity, identification and medical education: Why should we care? Med Educ 2010; 44: 40-9.

6. Costello CY. Professional identity crisis: race, class, gender and success at professional schools. Nashville (TN): Vanderbilt University Press; 2005.

7. Lee J, Graham MD. Student's perception of medical school stress and their evaluation of a wellness elective. Med Educ 2001;35:617-8.

CMAJ 2012. DOI:10.1503/cmaj.111453 